\title{
Research and Application of Key Technologies for Dynamic Control of Reservoir Water Level in Flood Season
}

\author{
Jun Zhang ${ }^{1, *}$, Yaowu Min ${ }^{1}$, Baofei Feng ${ }^{1}$ and Weixin Duan ${ }^{2}$ \\ 1 Bureau of Hydrology, Changjiang Water Resource Commission of the Ministry of Water Resource, \\ Wuhan 430010, China; minyw@cjh.com.cn (Y.M.); fengbf@cjh.com.cn (B.F.) \\ 2 Personnel Bureau, Changjiang Water Resource Commission of the Ministry of Water Resource, \\ Wuhan 430010, China; duanwx@cjh.com.cn \\ * Correspondence: zhangjun@cjh.com.cn
}

Citation: Zhang, J.; Min, Y.; Feng, B.; Duan, W. Research and Application of Key Technologies for Dynamic Control of Reservoir Water Level in Flood Season. Water 2021, 13, 3576. https://doi.org/10.3390/w13243576

Academic Editor: Enrico Creaco

Received: 29 October 2021

Accepted: 6 December 2021

Published: 13 December 2021

Publisher's Note: MDPI stays neutral with regard to jurisdictional claims in published maps and institutional affiliations.

Copyright: (c) 2021 by the authors. Licensee MDPI, Basel, Switzerland. This article is an open access article distributed under the terms and conditions of the Creative Commons Attribution (CC BY) license (https:/ / creativecommons.org/licenses/by/ $4.0 /)$.

\begin{abstract}
In today's reservoir operation study, it is urgent to solve the issues on improving flood resource utilization, maximizing reservoir impoundment, and guaranteeing water supply through real-time regulation optimization under the premise of ensuring flood control safety and taking risks properly. Based on previous studies, the key real-time operation technologies for dynamic control of reservoir water levels in flood season are summarized. The Danjiangkou Reservoir was taken as an example, the division of flood stages, reservoir water level requirements for improving water supply guarantee, dynamic control indexes of reservoir water level for beneficial use in stages during the flood season, and flood control dispatching indexes are proposed. Moreover, a practicable real-time flood forecast operation scheme for Danjiangkou Reservoir was compiled. Its application in 2017 indicated that the established scheme can provide strong technical support to ensure the overall benefits of Danjiangkou Reservoir, including flood control, water supply, and power generation.
\end{abstract}

Keywords: dynamic control; real-time forecast operation; pre-discharge dispatching

\section{Introduction}

Reasonable use of storage capacity for flood control and beneficial reservoir capacity, and flexible control of operating water level in flood season, can effectively exert the comprehensive benefits of the reservoir [1,2]. From the beginning of the 21st century, many scholars have focused on the control of reservoir flood limited water level (FLWL) and conducted a large deal of research. Qiu et al. [3] proposed a new concept of dynamic control of reservoir FLWL and its comprehensive reasoning mode. Ren et al. [4] studied the real-time dispatching method for dynamic control of reservoir FLWL through short-time rainfall forecast information. Li et al. [5] researched the water level operation of Three Georges Reservoir at different stages during the flood season based on the design flood by stages and pre-discharge forecast. Wang et al. [6] discussed the real-time dynamic control of reservoir water level by the real-time water regimen, rainfall information, the short-term rainfall and flood forecasts, and some other comprehensive information. Zhou et al. [7] explored the application of the real-time forecast operation technology for medium and small floods in the Three Georges Reservoir, which proved the technology not only ensured the flood control safety, but also achieved great beneficial use in operation of Three Georges Reservoir. Chen et al. [8] defined the dynamic control of reservoir operating water level and proposed a method to perform risk analysis and assessment over the regulation results. Due to the differences in hydrometeorological characteristics and the contradiction between water resources supply and demand, foreign reservoirs generally used a single FLWL in the past [9]. In the early 1980s, the US Army Corps of Engineers proposed the "redistribution of reservoir capacity" [10]. Wurbs et al. [11] redistributed the storage capacity of reservoirs in Brazos Basin, Texas, USA according to the seasonal variation characteristics of floods, and obtained the relatively reasonable FLWL of reservoirs in different periods. In the 21st 
century, Cunderlik et al. [12] applied the relative frequency and vector statistics to the study of reservoir flood season staging. Beurton et al. [13] proposed the cluster analysis to divide the flood season using the statistics of flood data of 481 hydrological stations in Germany. In recent years, much research has focused on real-time flood dispatching. Chang [14] used genetic algorithm as a search engine for solving formulation of reservoir flood operation to find a global optimum of a mixture of mathematical and nonmathematical formulations. Malekmohammadi et al. [15] established a real-time operation optimization model for flood management, and they proved that this model can be effectively used for realtime operation of cascade river-reservoir systems. Che et al. [16] further studied the optimization model for real-time flood-control operation of river-reservoir systems, then presented the development and testing of a methodology for determining reservoir release schedules before, during, and after an extreme flood event in real time. Water resources managers face challenges balancing conflicting goals in reservoir operation given the uncertainties introduced by climatic change. Ashofteh et al. [17] used multi-objective genetic programming to calculate optimal reservoir-operating rules under baseline and climatic-change conditions. Ahmadi et al. [18] studied the adaptive reservoir operation rules under climatic change, and these results establish the importance of factoring in climatic change and considering adaptive strategies in future reservoir operations.

The FLWL, determined by the annual design floods and reservoir operation in the planning and designing stage, is the most significant parameter of tradeoff between impoundment and discharge of reservoirs [19]. The traditional FLWL based on the annual design flood hydrograph usually has only one value for the whole flood season [20]. However, application of the annual fixed FLWL for the whole flood season neglects annual and seasonal variation of inflow, which may lead to water shortage when the flood season is delayed or ends ahead [21]. There are two existing approaches to increase water storage of a reservoir [22]. One is a multiple duration limiting water level, which employs a multiple duration design rainfall. The other is the dynamic control of FLWL, i.e., the water level can fluctuate within dynamic control bounds [23]. In recent years, a great number of research and practical applications concerning the dynamic control of FLWL have been carried out. Chen et al. [24] suggested that the maximum available flood prevention storage was determined by the current reservoir storage, flood control objectives, and forecast information. Jiang et al. [25] took the forecasting error as a fuzzy variable to optimize the dynamic control bound of FLWL. The theories and methods for reservoir water level control in flood season have been gradually improved. However, the existing research mostly focuses on the regulation of medium and small floods for beneficial use, rarely incorporating the flood control regulation into the dynamic control of reservoir water level in flood season, and has deficiencies in technical details for real-time operations.

This paper, based on previous research, summarizes the key real-time operation technologies for dynamic control of reservoir water level in flood season. Taking Danjiangkou Reservoir as an example, some achievements are put forward, such as the division of flood stage, and the reservoir water level demand that improves water supply guarantee rate. Accordingly, a practicable real-time flood forecast operation scheme for Danjiangkou Reservoir is developed. It can provide strong technical supports to ensure the overall benefits of Danjiangkou Reservoir, including flood control, water supply, and power generation. The technical route of this paper is shown in Figure 1. 


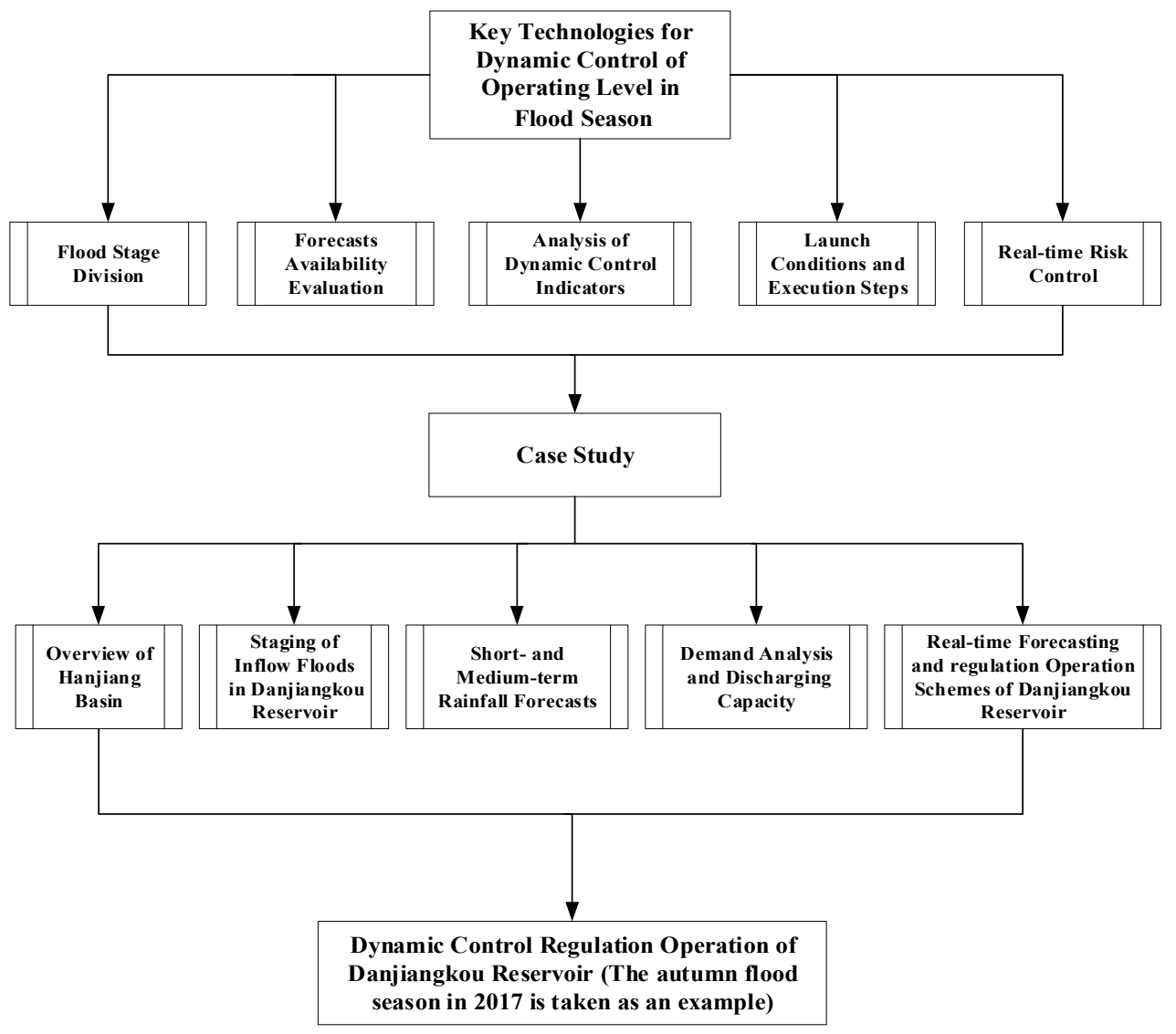

Figure 1. Technical route of this paper.

\section{Key Technologies for Dynamic Control of Operating Level in Flood Season}

The main idea of dynamic control of operating level in flood season is to make full use of all available forecast information and take flood control risks seriously. The reservoir water level should be controlled in a safe and economic range to ensure the flood control safety and fully utilize the flood resources [26]. The flood control risk of reservoir is related to the inflow flood volume. Therefore, the flood regulation categories and dynamic control ranges of operating water level can be defined considering inflow flood magnitude (Figure 2). For any flood below the compensative operation criteria for the protection objects downstream the reservoir, the flood control is not required and the operation for beneficial use based on pre-discharge forecast is recommended. The principle is impounding flood which can be pre-discharged within the effective forecast period, to ensure the reservoir can be pre-discharged to the FLWL before the great flood comes. For any flood between the downstream compensative operation criteria and 20-year return period, there are certain flood control risks. It is recommended to implement the flood control operation considering both the proper flood control risks and the beneficial use, and to reserve adequate reservoir capacity for the most adverse potential flood. For any flood between 20-year return period and the design criteria of downstream protection object, there are great flood control risks. It is recommended to perform the flood control operation by stages starting from the flood control water level. For any flood above the downstream protection object design criteria, there are quite great flood control risks. It is barely possible for dynamic water level control, and the primary goal is to ensure the dam safety based on the operation as stated in the Procedures [27].

The above main idea and contents reveal that, the dynamic control involves the launching, definition, and connection of different operations for water level rising, predischarge forecast, flood control, and reservoir impoundment, as well as risk prevention and control. The key technologies associated shall include the division of flood stage, 
forecasts availability evaluation, analysis of dynamic control indexes, determination of application conditions and steps, real-time risk prevention and control, etc.

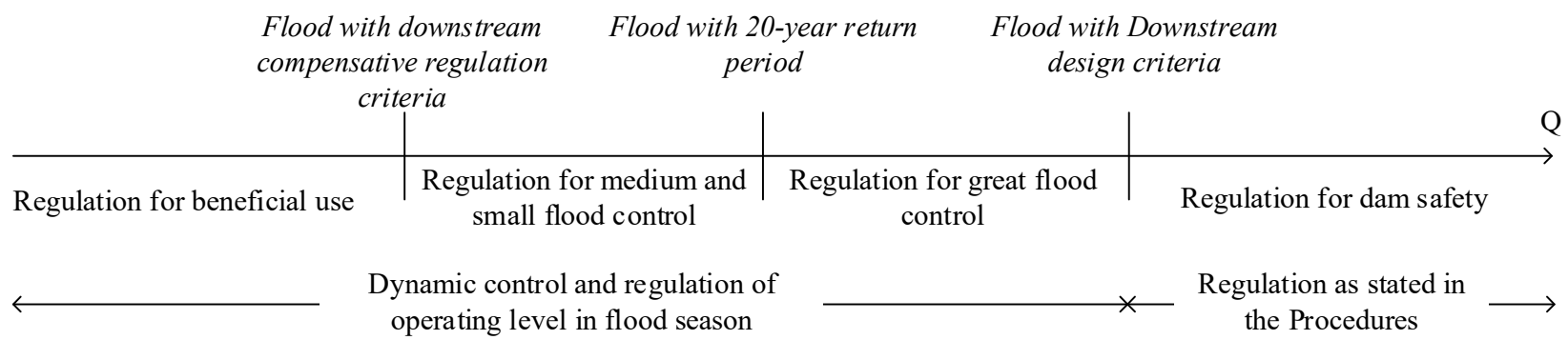

Figure 2. Application scope of dynamic control technologies of operating level in flood season.

\subsection{Flood Season Stage Division}

Floods within the basin are generally generated by rainstorms, with obvious seasonal variations, getting stronger and then weaker from the beginning to the end of the flood season. The flood season in a certain basin generally has a constant staging feature [28]. Fully understanding the seasonal characteristics of flood in the basin where the reservoir is located and dividing the flood into flood season stages can provide a key basis for the dynamic control of flood season water level.

The methods of dividing flood season are fuzzy analysis, runoff characteristic statistical analysis, in-order cluster analysis and others $[9,19,20]$, the runoff characteristic statistical analysis is used in this paper. The scatter distribution of annual maximum flood peaks, distribution of maximum N-day flood volumes, daily average runoff process for years at the dam site are analyzed. After combining the statistics with the climate conditions, dam site and downstream flood rules, the stages of the flood season can be determined.

\subsection{Forecasts Availability Evaluation}

The traditional reservoir operation is only based on the statistics of historical floods, to prevent small probability floods of the design and verification level [29]. With the development of modern technology, the forecasting technology which integrates long-, medium-, and short-term forecasts and couples meteorological and hydrological conditions is more reliable to predict the possible floods within a certain period in future [1], providing a prerequisite for dynamic control of operating level in flood season.

The reliable and prompt hydro-meteorological forecast is fundamental for determination of pre-discharge forecast indexes and for dynamic control of operating level. Therefore, to evaluate the availability of forecast information, two main aspects are considered: effective forecast period and forecast accuracy.

\subsubsection{Effective Forecast Period (T)}

The forecast period determines the pre-discharging time and is one of pre-discharge capacity restraints. Its main restraining conditions are the quantitative rainfall forecast period, the characteristics of runoff generation and concentration and forecasted calculations of the basin, time for regulation decision-making and operation, and can be calculated by the following equation.

$$
T=T_{p}+T_{h}-T_{w}
$$

where $T_{p}$ represents the rainfall forecast period and generally a time point with sudden decline of rainfall forecast accuracy within a short term; $T_{h}$ is the time from the moment when the heavy rainfall starts in the basin upstream the reservoir to the moment when the inflow flood reaches the downstream safety discharge $q_{o u t}$; and $T_{w}$ is the time for information collection and transmission, forecast generation, decision-making and discussion, gate and unit operations, etc. 


\subsubsection{Forecast Accuracy}

As the information available for dynamic control of operation level in flood season includes rainfall forecast and water regime prediction, it is necessary to evaluate the forecast accuracy separately. The analysis of short-term rainfall forecast accuracy is generally based on the practices of the meteorological departments. The threat score (TS) method is applied, i.e., to quantify the accuracy, missed report rate, and false rate of rainfall forecasts at different levels, and to analyze the frequency distribution of the actual rainfalls within a certain magnitude of rainfall forecasts. For the medium-term forecast, the qualified rate is used to evaluate the coverage of the heavy rainfall process. The flood forecast accuracy for the reservoir mainly covers two parts: inflow floods and downstream control objects. By reference to the Standard for Hydrological Information and Hydrological Forecasting in China [30], the qualified rate and error statistics are based on the inflow flood peak discharge, maximum flood regulation level, flood peak at downstream control station, and some other factors. According to the regulation demands, the uncertainty of forecast outcomes is analyzed and evaluated, scientific decisions are made, and the risks are controlled.

\subsection{Analysis of Dynamic Control Indicators}

\subsubsection{Safety Discharge}

Another constraint to the pre-discharge capacity of a reservoir is the safety discharge of the reservoir $q_{\text {out }}$ to safeguard the downstream protection objects. The safety discharge is a dynamic indicator, and mainly affected by the change of erosion and siltation at the sections, the change of stage-discharge relation and the lateral inflow between the reservoir dam and the downstream projection objects. The safety discharge $Q_{s}$ of the downstream projection objects can be determined by the water level indicator $\mathrm{H}$ (generally warning water level or safety guarantee water level) based on the stage-discharge relation of the protection objects. Then the safety discharge of the reservoir can be determined and expressed mathematically as a function of the lateral inflow $q_{l}$, the forecast errors, flatness along the riverway, and some other factors, i.e.,

$$
q_{\text {out }}=f\left(Q_{s}, q_{l}\right)-\varepsilon_{q}
$$

where $f$ represents a river flow routing function; $\varepsilon_{q}$ is the discharge forecast error of lateral inflow.

\subsubsection{Analysis of Water Level Rise}

The basic idea for analysis of pre-discharge forecast water level control index is that once the conditions for pre-discharging are met, the reservoir will discharge at the safety discharge $q_{o u t, t}$ within the effective forecast period, to reduce the reservoir water level to the FLWL. During this process, the water volume discharged is the pre-discharge capacity, and the water level at this time is the allowable rise $\Delta Z$ above the FLWL, to be calculated by the following equation:

$$
\Delta Z=F\left[\sum_{t=t_{c u}}^{t_{c u}+T_{\mathrm{fu}}}\left(q_{f u}-q_{i n, t}\right) \times \Delta t+\sum_{t=t_{c u}+T_{\mathrm{fu}}}^{t_{c u}+T}\left(q_{o u t, t}-q_{i n, t}\right) \times \Delta t\right]-\varepsilon_{\mathrm{Z}}
$$

where $\Delta \mathrm{Z}$ represents the upper limit of the rise above the FLWL at $t_{0} ; F$ is a function converted from the reservoir water level corresponding to the pre-discharge; $q_{i n, t}$ is the forecasted inflow process within the effective forecast period $T ; t_{c u}$ is the start time for dynamic control of reservoir water level, $t_{c u}=t_{0}+T_{w}$ and $t_{0}$ is the base time for operational forecast; $T_{\mathrm{fu}}$ is the duration from the inflow discharge at $t_{0}$ to the full discharge; $\varepsilon_{\mathrm{z}}$ is the water forecast error. Generally, the typical historical great floods at different stages of the flood season are sampled to research and determine the calculated $\Delta Z_{i}$, then the water level rise indicator at each stage can be obtained. 


\subsubsection{Flood Control Indicators}

(1) Flood control operation for medium and small floods

When the medium and small floods (less than once in 20 years) occur and the reservoir is not fully undertaking flood control, they will cause unnecessary downstream flood control stress. When the water level of the reservoir rises too high during flood control, it will also cause its own excessive flood control pressure. To avoid the above two situations, the control index of reservoir water level should be analyzed. The specific idea is that, according to the historical actual floods, enough capacity should be reserved to resist against the most adverse flood within this stage. The maximum flood regulation level should consider the smaller impact of backwater submergence in the reservoir area. Based on high water level for flood control, and the excessive water volume of the historical maximum flood by stages above $q_{o u t}$, the maximum allowable initial water levels of reservoir at different stages can be calculated by:

$$
Z_{0}=F\left[F\left(Z_{f c}\right)-W_{e x}\right]
$$

where $Z_{0}$ is the maximum allowable initial water level, and $Z_{f c}$ represents the flood control high water level, $W_{e x}$ is the excessive water volume of the historical maximum flood by stages above $q_{\text {out }}$.

(2) Flood control operation for great floods

When a large flood (between 20-year return period and the downstream design criteria) is forecast, the initial water level for reservoir regulation is the flood limited water level. However, the way to determine the compensative discharge based on the flood and understanding the possible maximum flood regulation level, directly relates to the risk control and flood control benefits. The formulation of flood control dispatching modes in the Procedures [27] is rough in terms of the inflow flood magnitudes and the compensative regulation discharges. The benefits of flood control dispatching cannot be optimal because the less probable floods are considered too much.

In practice, typical historical floods can be divided by magnitude based on inflow flood peak, maximum flood volume, and flood peak of downstream protection sections. The flood control compensation discharge grades are divided considering the flood control situation in the downstream. According to the current engineering conditions, the flood control simulation operation can be carried out for each flood with full reference to the compensation discharge grades and flood control benefits. Finally, the flood control operation indicators of flood $Q_{\mathrm{in}, \mathrm{i}}$ at each magnitude are determined (compensative discharge $Q_{\text {com }, \mathrm{i}}$ and maximum flood regulation level $Z_{\mathrm{max}, \mathrm{i}}$ ).

\subsection{Launch Conditions and Execution Steps}

The core for dynamic control of operating level in flood season is to research and determine the situations in a real time manner based on the available information, and to switch over the operation for flood control or beneficial use; therefore, it is required to define the launch conditions and execution steps for these two regulation modes.

\subsubsection{Launch Conditions}

The prerequisites for dynamic control of operating level in flood season is to make full use of hydro-meteorological forecasts, and to take flood control risks properly but neither compromise the flood control standards of the reservoir nor increase the burden on the downstream flood control. Therefore, the launch conditions shall cover the forecast information and the upstream and downstream flood control situations, and these can be summarized in Table 1. 
Table 1. Conditions for Launching Dynamic Control of Operating Level in flood season.

\begin{tabular}{|c|c|c|c|c|}
\hline Flood Grade & Regulation Mode & & Start-Up Conditions & Notes \\
\hline $\begin{array}{l}\text { Downstream compensative } \\
\text { operation or below }\end{array}$ & $\begin{array}{l}\text { Regulation for } \\
\text { beneficial use }\end{array}$ & $\begin{array}{l}\text { (2) } \\
\text { (3) }\end{array}$ & $\begin{array}{l}\text { Within the forecast period, the inflow flood } \\
\text { peak is less than } q_{\text {out }} \text { or the peak occurs, and } \\
\text { the flood discharge is declined to } q_{\text {out }} \text { or } \\
\text { below, the weather conditions get better, and } \\
\text { the flood intends to recede; } \\
\text { The water level at downstream is low, } \\
\text { generally not above the warning water level; } \\
\text { There is no obviously systematic heavy } \\
\text { rainfall in the areas upstream and } \\
\text { downstream of the reservoir and there is } \\
\text { little likelihood of a large flood at present } \\
\text { and within the forecast period. }\end{array}$ & $\begin{array}{l}\text { All conditions } \\
\text { fulfilled }\end{array}$ \\
\hline
\end{tabular}

(1) Within the forecast period, the inflow flood peak is greater than $q_{o u t}$ but there is little likelihood of a large flood, the weather conditions get better and the water inflow forecasts are accurate;

Between the downstream
compensative operation to 20-year return period
Regulation for medium and small flood control
(2) The flood control departments have certain flood control needs;

(3) The integrated regulation benefits are required.
Any one of the conditions fulfilled
(1) When a large flood is forecasted;

(2) When the downstream flood control is intense, and the water level goes beyond the warning or safety water level at key control sections.
Any one of the conditions fulfilled

\footnotetext{
Between 20-year return period to the downstream design criteria
}

Regulation for large flood control 
(6) At the end of flood season, without compromising the flood control safety, it is possible to impound the water to increase the full storage ratio of the reservoir.

\subsection{Real-Time Risk Control}

As the rainfall and flood forecasts are within a limited forecast period and have errors (absolute error, relative error, and deterministic coefficient are generally selected as the indexes to evaluate the uncertainty of forecasts), there must be certain risks for dynamic regulation of operating level. In actual operations, the dynamic control associated indicator system may be used for risk control, and the regulation policies may be adjusted timely and properly as the flood and rainfall vary currently and within the forecast period. Meanwhile, some measures may be taken to improve the risk prevention and control by enhancing the monitoring and information sharing, improving forecasting and prediction capabilities, and establishing a joint operation mechanism for a multi-reservoir system in the basin.

\section{Case Study}

The procedures of dynamic control of the operating water level of a single reservoir in flood season are as follows: (a) If the rainstorm and flood of the basin where the reservoir is located have obvious seasonal characteristics, the stage of flood season should be divided first; (b) Collect rainfall and flood predictions in the history of the reservoir, evaluate the availability of the prediction results of the reservoir, and obtain the prediction accuracy, prediction period and other indicators; (c) The dynamic control water level rise indicator at different stages of flood season can be obtained by forecasting pre-discharge technologies and integrated flood control risks; (d) Establish launch conditions and execution steps, and technical scheme of real-time forecast and dispatching; (e) Formulate emergency measures to ensure real-time control of flood control risks in case of large deviations in the forecast. According to the above procedures, this paper takes Danjiangkou Reservoir as an example to carry out research.

\subsection{Overview of Hanjiang Basin}

Hanjiang, the largest tributary of the middle reaches of the Yangtze River [31], spans 6 provinces (cities) and flows into the Yangtze River in Wuhan. The total length is $1577 \mathrm{~km}$ and drainage area is $159,000 \mathrm{~km}^{2}$. The Hanjiang basin is shown in Figure 3. The upper part of the Danjiangkou is upstream. It is dominated by middle and low mountains, with deep valleys, steep slopes on both sides, and rapid water flow and many river beaches [32]. The flood is mainly caused by rainstorm, and the spatial and temporal distribution of flood is consistent with that of rainstorm. The Hanjiang basin belongs to the subtropical monsoon climate zone of East Asia. The flood has obvious stage characteristics: From 21 June to 20 August is the summer flood season, which is generally the whole regional flood; Autumn flood season is from 21 August to 16 October, and floods usually come from upstream areas and are mostly continuous flood peaks with long duration and high flood peaks. The middle and lower reaches of Hanjiang are the key areas for flood control. Nowadays, a comprehensive flood control system has been built based on dikes, with Danjiangkou Reservoir as the backbone and other projects as coordination.

The heightening project of Danjiangkou Reservoir is divided into two phases: the first phase was completed in 1974, and the second phase was completed in 2013. Its crest elevation is $176.60 \mathrm{~m}$. The normal high-water level, design flood level, and check flood level are $170.00 \mathrm{~m}, 172.20 \mathrm{~m}$, and $174.35 \mathrm{~m}$ respectively. The dead storage capacity and beneficial reservoir capacity are 11.08 billion $\mathrm{m}^{3}$ and 16.12 billion $\mathrm{m}^{3}$ respectively. With the continuous and rapid development of Hanjiang basin, the contradiction between flood control and water storage of Danjiangkou Reservoir has become increasingly prominent. A new situation of water control has put forward higher requirements for comprehensive utilization of water resources. For Danjiangkou Reservoir, it is urgent to impound as much water as possible for better water supply guarantee and to give a full play to its 
overall benefits upon optimized regulation under the premising of ensuring the flood control safety.

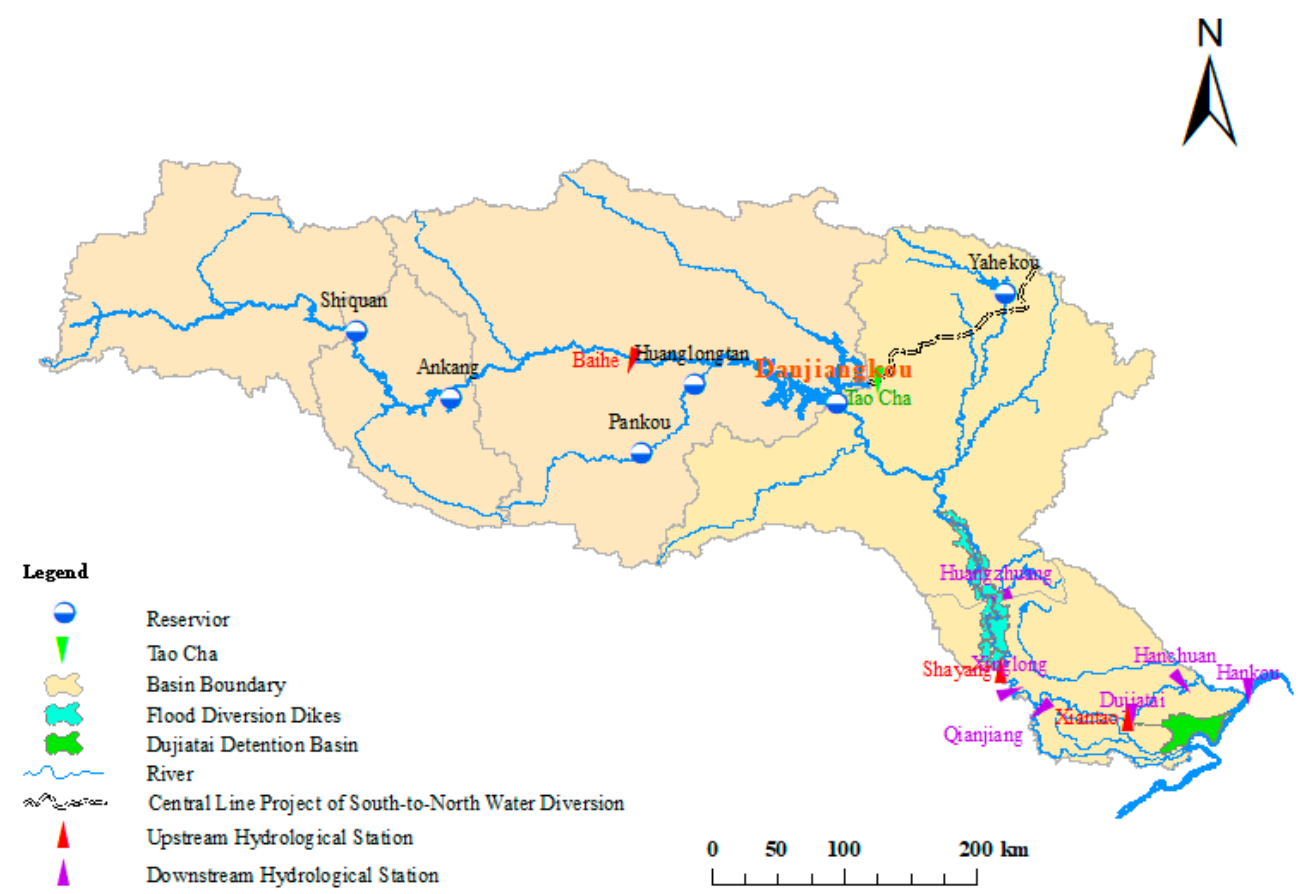

Figure 3. The schematic diagram of the Hanjiang Basin.

\subsection{Staging of Inflow Floods in Danjiangkou Reservoir}

Based on the investigation and measured (1929-2015) data of maximum flood peak flow in Danjiangkou Reservoir, flood and daily flow data at Danjiangkou-Huangzhuang Section from 1954 to 2015, the statistical chart of occurrence time of annual maximum flood peak, scatter chart of annual maximum flood peak flow, and daily average flow process chart were drawn in Figures 4-6.

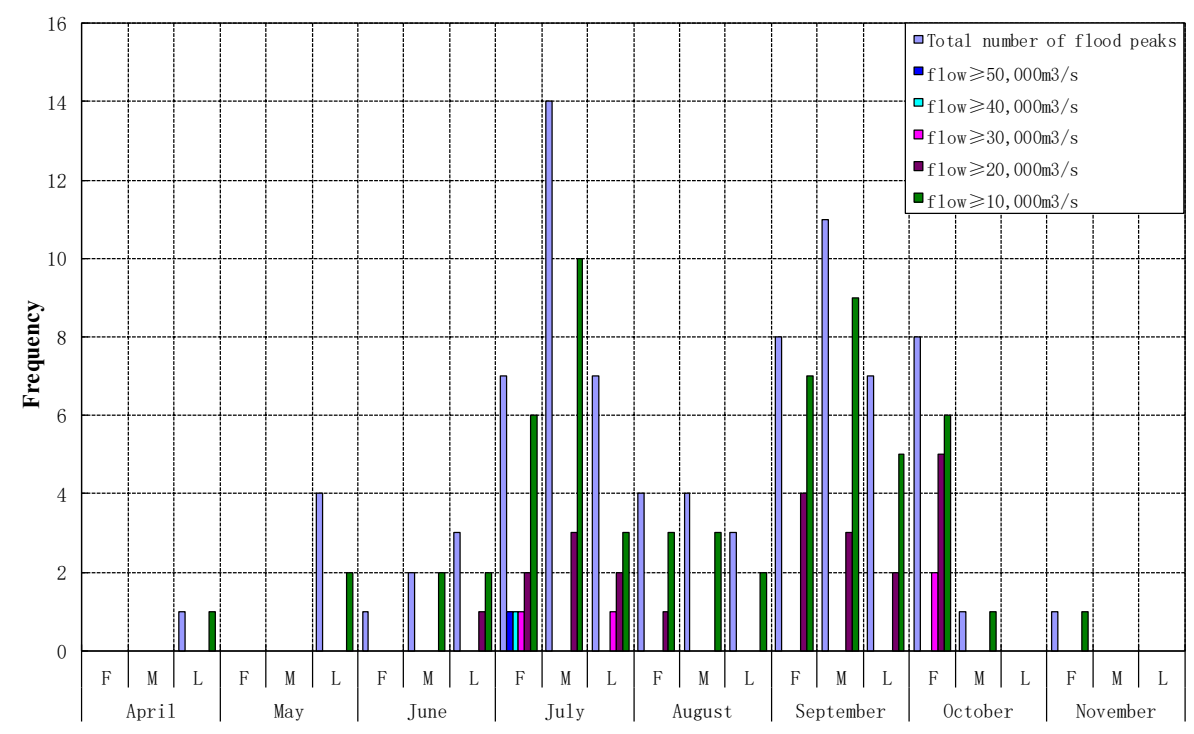

Figure 4. The statistical chart of occurrence time of annual maximum flood peak. Notes: $\mathrm{F}$ is the first ten-day period of a month; $\mathrm{M}$ is the middle ten days; $\mathrm{L}$ is the last ten days. The total number of flood peaks includes the flood events below $10,000 \mathrm{~m}^{3} / \mathrm{s}$. 


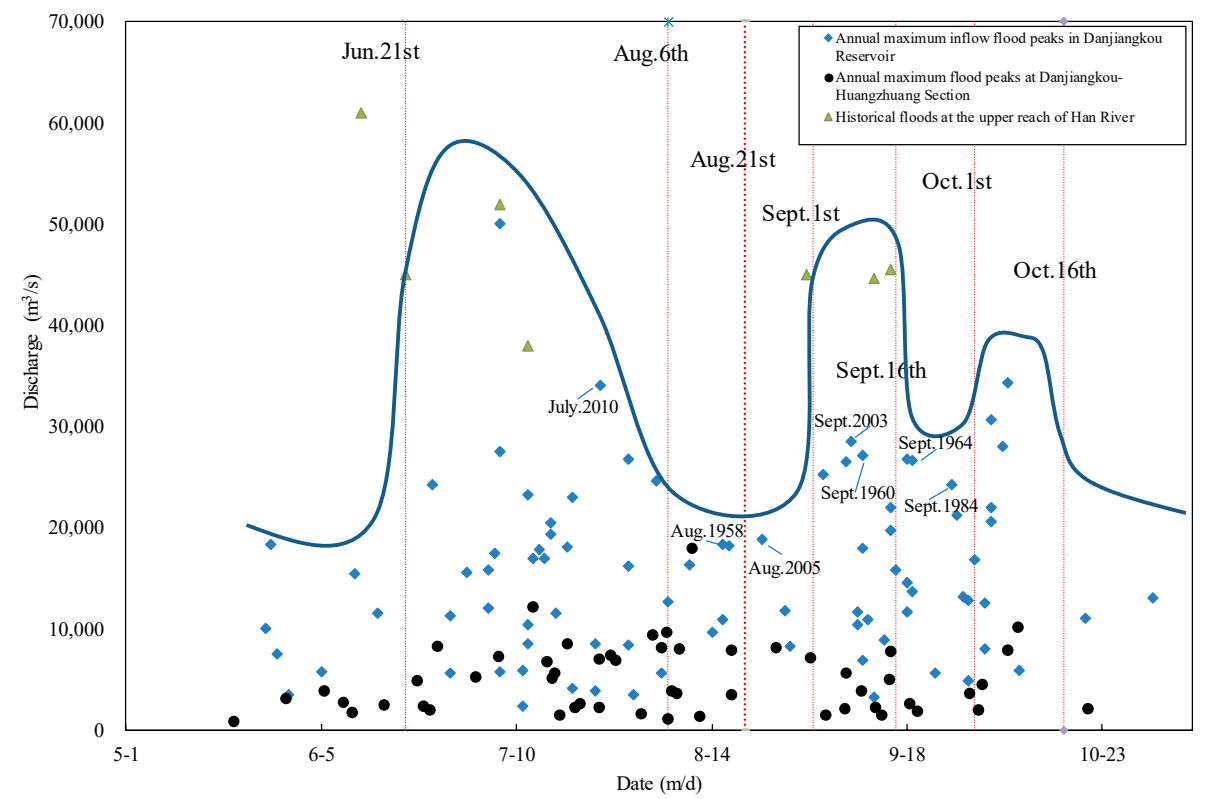

Figure 5. Scatter chart of annual maximum flood peak in Danjiangkou Reservoir.

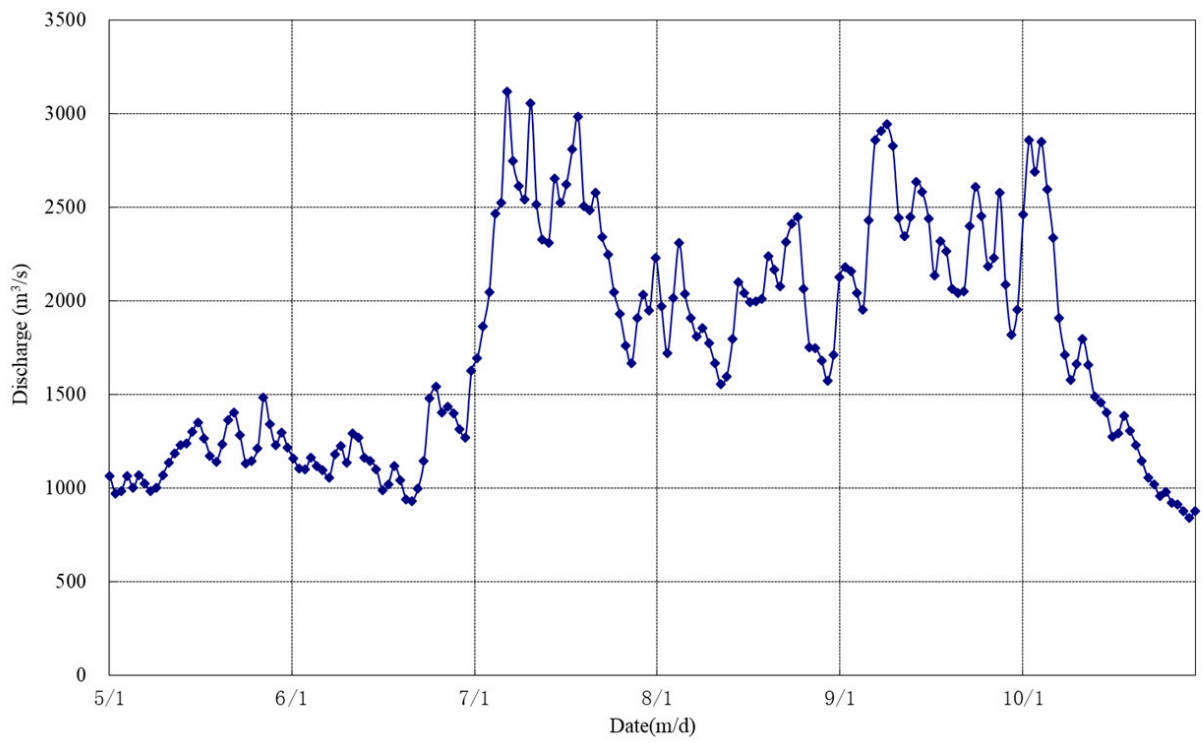

Figure 6. Daily average flow process in Danjiangkou Reservoir.

According to the point data of investigated flood and actual historical flood, the historical flood outsourcing line was obtained, which is the blue line in Figure 5. Combining the demarcation point of summer flood and autumn flood, historical floods and practical experience, it can be inferred that the blue outsourcing line in the flood season from 21 June to 16 October presents the shape of "three peaks and two valleys". The flood season of Danjiangkou Reservoir can be preliminarily divided into five stages: 21 June to 5 August, 6 August to 31 August, 1 September to 15 September, 16 September to 30 September, and 1 October to 16 October. In the design of the reservoir, it has been demonstrated that 21 August is the demarcation point of summer flood and autumn flood, so 6 August-31 August is further subdivided into 6 August-20 August and 21 August-31 August. Finally, the flood season of Danjiangkou Reservoir can be divided into 6 stages: main summer flood season (21 June-5 August), end stage of summer flood season (6 August-20 August), early stage of autumn flood season (21 August-31 August), mid- 
dle autumn flood season (1 September-15 September), transitional period of autumn flood season (16 September-30 September), and the end flood season (1 October-16 October).

In the main summer flood season, there is a large likelihood of floods at the upper and middle reaches of Hanjiang River. From 6 August to 30 September, the likelihood is not high at the upper and middle reaches, especially in September with a lower probability. In the end of flood season, although the probability is great, the floods at DanjiangkouHuangzhuang Section are mostly of small magnitudes.

\subsection{Short- and Medium-Term Rainfall Forecasts}

The rainfall and flood forecast data from 2003 to 2015 were sampled to evaluate the availability of Hanjiang River forecast information. According to the watershed rainfall forecast standard formulated by Hydrological Bureau of Yangtze River Water Resources Commission listed in Table 2, short-term rainfall forecast score statistics were carried out. The average scores of short-term rainfall forecasts are 90.3, 87.7, and 85.6 respectively for $24 \mathrm{~h}, 48 \mathrm{~h}$, and $72 \mathrm{~h}$ quantitative rainfall forecasts in Hanjiang basin. The accuracy of mid-term forecast to heavy rainfall is evaluated by the qualified rate $(\mathrm{QR})$, as shown in Equation (5). Specifically, when the forecast error is less than the allowable error (the maximum allowable error determined by the application requirements of forecast results and the actual forecast technology level), it is a qualified forecast. The QRs of heavy rainfall forecasts are $92.1 \%$ and $70.4 \%$ individually in the upper reach, and the middle and lower reaches of Hanjiang River in a middle term (4-7 days).

$$
\mathrm{QR}=\frac{Q F T}{T F T}
$$

where $Q F T$ is the qualified forecast times and TFT is the total forecast times.

Table 2. Short -term Rainfall Forecast evaluation of Yangtze River Hydrologic Information \& Forecast Center.

\begin{tabular}{|c|c|c|c|c|c|c|c|c|c|c|c|}
\hline Forecast $(\mathrm{n}$ & 0 & $1-5$ & $5-10$ & $5-15$ & $10-20$ & $15-25$ & $20-40$ & $30-50$ & $40-60$ & 50-100 & $>100$ \\
\hline $\mathrm{R}=0$ & 100 & 80 & 0 & 0 & 0 & 0 & 0 & 0 & 0 & 0 & 0 \\
\hline $0<\mathrm{R} \leq 5$ & 80 & 100 & 90 & 80 & 80 & 60 & 0 & 0 & 0 & 0 & 0 \\
\hline $5<\mathrm{R} \leq 10$ & 0 & 80 & 100 & 100 & 90 & 80 & 60 & 0 & 0 & 0 & 0 \\
\hline $10<\mathrm{R} \leq 15$ & 0 & 60 & 90 & 100 & 100 & 90 & 80 & 60 & 0 & 0 & 0 \\
\hline $15<\mathrm{R} \leq 20$ & 0 & 40 & 80 & 90 & 100 & 100 & 90 & 80 & 60 & 0 & 0 \\
\hline $20<\mathrm{R} \leq 25$ & 0 & 0 & 60 & 80 & 90 & 100 & 100 & 90 & 80 & 60 & 0 \\
\hline $25<\mathrm{R} \leq 30$ & 0 & 0 & 40 & 60 & 90 & 90 & 100 & 90 & 90 & 80 & 40 \\
\hline $30<\mathrm{R} \leq 40$ & 0 & 0 & 0 & 40 & 80 & 90 & 100 & 100 & 90 & 90 & 60 \\
\hline $40<\mathrm{R} \leq 50$ & 0 & 0 & 0 & 0 & 60 & 80 & 90 & 100 & 100 & 90 & 80 \\
\hline $50<\mathrm{R} \leq 60$ & 0 & 0 & 0 & 0 & 40 & 60 & 90 & 90 & 100 & 100 & 90 \\
\hline $60<\mathrm{R} \leq 80$ & 0 & 0 & 0 & 0 & 0 & 40 & 80 & 90 & 90 & 100 & 90 \\
\hline $80<\mathrm{R} \leq 100$ & 0 & 0 & 0 & 0 & 0 & 20 & 80 & 80 & 90 & 100 & 100 \\
\hline$<1 \overline{-100}$ & 0 & 0 & 0 & 0 & 0 & 0 & 60 & 80 & 90 & 90 & 100 \\
\hline
\end{tabular}

Notes: $\mathrm{R}$ is rainfall. When the actual rainfall is 0 and the forecast is 0 , the rainfall forecast score is 100 .

The forecast accuracy of inflow floods in Danjiangkou Reservoir was evaluated. The QRs of flood peak discharge are $93 \%$ and $88 \%$ respectively for $24 \mathrm{~h}$ and $48 \mathrm{~h}$. The QRs of water regime forecasts at Huangzhuang are $90.5 \%$ and $80 \%$ respectively for $48 \mathrm{~h}$ and $72 \mathrm{~h}$.

The comprehensive analysis shows that, the effective forecast period is 2 days for rainfall forecasting in Hanjiang basin, which can provide scientific basis for reservoir operation and management. If no rain is forecasted or only light rains are forecasted within $48 \mathrm{~h}$, the probability of heavy rain or larger magnitude of rainfalls is quite low. The medium-term forecasts enable the understanding of systematic rainfalls in the Hanjiang basin 5-7 days in advance. The flood and rainfall forecasting in Hanjiang basin is highly 
accurate, creating favorable conditions for dynamic control of operating water level of Danjiangkou Reservoir in real time.

\subsection{Demand Analysis and Discharge Capacity}

\subsubsection{Flood Control Demand Analysis}

Under the premise of ensuring its own safety, the flood control operation in Danjiangkou Hydro Project [28] is to combine embankments and detention basins, to meet the flood control requirements at the middle and lower reaches of Hanjiang River. It should also share the flood control pressure in the middle and lower reaches of the Yangtze River when necessary. In case of a great flood equivalent to July 1935 flood (with a 100-year return period) at the middle and lower reaches of Hanjiang River, the upstream inflow is impounded by the reservoir. At the same time, Dujiatai detention basin and some protective embankments at the middle and lower reaches are used for flood diversion, to ensure flood control safety. In case of any floods below July 1935 flood magnitude, the upstream inflow impoundment of the reservoir will reduce the possibility to utilize Dujiatai detention basin and protective embankments at the middle and lower reaches.

According to the Procedures [27], the Huangzhuang (Nianpanshan) reach is set as the compensative operation target of Danjiangkou Reservoir. It is important to evaluate the flood control situation in the middle and lower reaches of Hanjiang River whether the main hydrology stations (Shayang and Xiantao) are above the warnings, and whether Dujiatai detention basin and protective embankments are put into use. The correlation between Huangzhuang and Xiantao sections is determined according to the historical data, and the floods with the return period less than 100 years are analyzed considering the Procedures [27]. Based on these results, the compensative operations of Danjiangkou Reservoir to Huangzhuang Station may be classified into the following 6 grades (Table 3).

Table 3. Compensative operations at the middle and lower reaches of Hanjiang River $\left(\mathrm{m}^{3} / \mathrm{s}\right)$.

\begin{tabular}{|c|c|c|c|}
\hline Grade & Discharge at Huangzhuang & Discharge at Xiantao & $\begin{array}{l}\text { Flood Control Situation at the Middle and } \\
\text { Lower Reaches }\end{array}$ \\
\hline 1 & 8000 & 5600 & No flood stresses. \\
\hline 2 & 10,000 & 7000 & $\begin{array}{l}\text { The flood control is under slight stress, and water } \\
\text { levels at main stations are generally below the } \\
\text { warning water level. }\end{array}$ \\
\hline 3 & 12,000 & 8000 & $\begin{array}{l}\text { When the water level at Shayang Station is near } \\
\text { the warning water level, and the water level at } \\
\text { Hankou is below the warning water level, the } \\
\text { flood diversion is not required at Dujiatai. }\end{array}$ \\
\hline 4 & 16,000 & 11,000 & $\begin{array}{l}\text { When the water level at Huangzhuang reaches the } \\
\text { warning water level, only Dujiatai floodway is } \\
\text { adequate for flood diversion, to ensure the safety } \\
\text { at the lower reach of Hanjiang River. }\end{array}$ \\
\hline 5 & 18,000 & 13,000 & $\begin{array}{c}\text { Beside Dujiatai Floodway, the flood detention } \\
\text { areas are also required for flood storage and } \\
\text { diversion, to ensure the safety at the lower reach of } \\
\text { Hanjiang River. }\end{array}$ \\
\hline 6 & 20,000 & 14,000 & $\begin{array}{l}\text { The water level at Shayang Station is near the } \\
\text { safety water level, and beside the flood storage } \\
\text { and detention areas, the protective embankments } \\
\text { are also required for flood diversion. }\end{array}$ \\
\hline
\end{tabular}

Notes: The discharges and corresponding flood control situations in Table 3 are calculated by repeated trial calculations using hydraulic models in the middle and lower reaches of the Hanjiang River according to typical flood processes. 
3.4.2. Analysis of Operating Water Level Indicators Meeting the Water Supply Demand of Danjiangkou Reservoir

By reference to the General Report on Feasibility Study of Central Line Project of Southto-North Water Diversion (Phase I) [33] and the Procedures for operation of Danjiangkou Reservoir [27], water demand and water supply dispatching modes were analyzed. Based on these, the design demand of typical year at $50 \%$ frequency was taken as the typical water supply process for Danjiangkou Reservoir. On the condition that the water level falls to $150 \mathrm{~m}$ at the end of April of next year, according to the actual inflow on a time scale of 10 days, the control values of water level from 1952 to 2015 can be calculated by reverse sequential recursion year by year considering 1-year and 2-year water supply respectively. The 64-year data of the same time node were sorted and the water levels under different guarantee rates were calculated by empirical frequency method. By connecting the water level control values of each time node at the same guarantee rate, the water level control line at this water supply guarantee rate can be obtained, as shown in Figure 7.

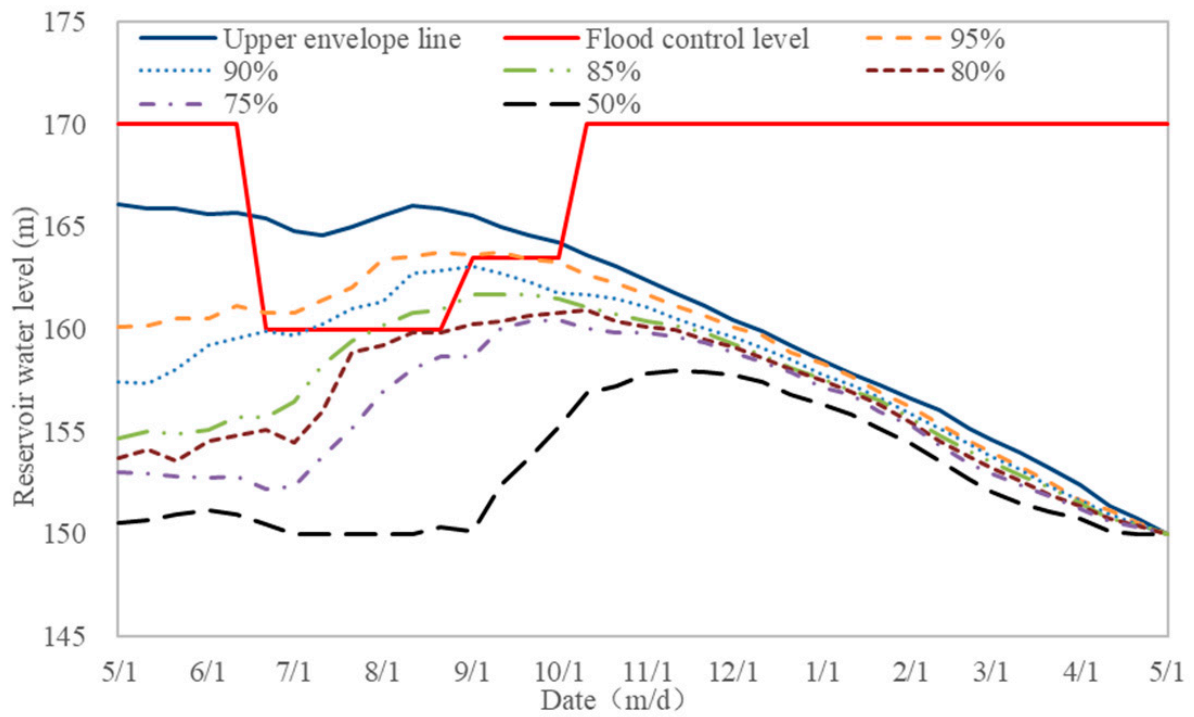

(a)

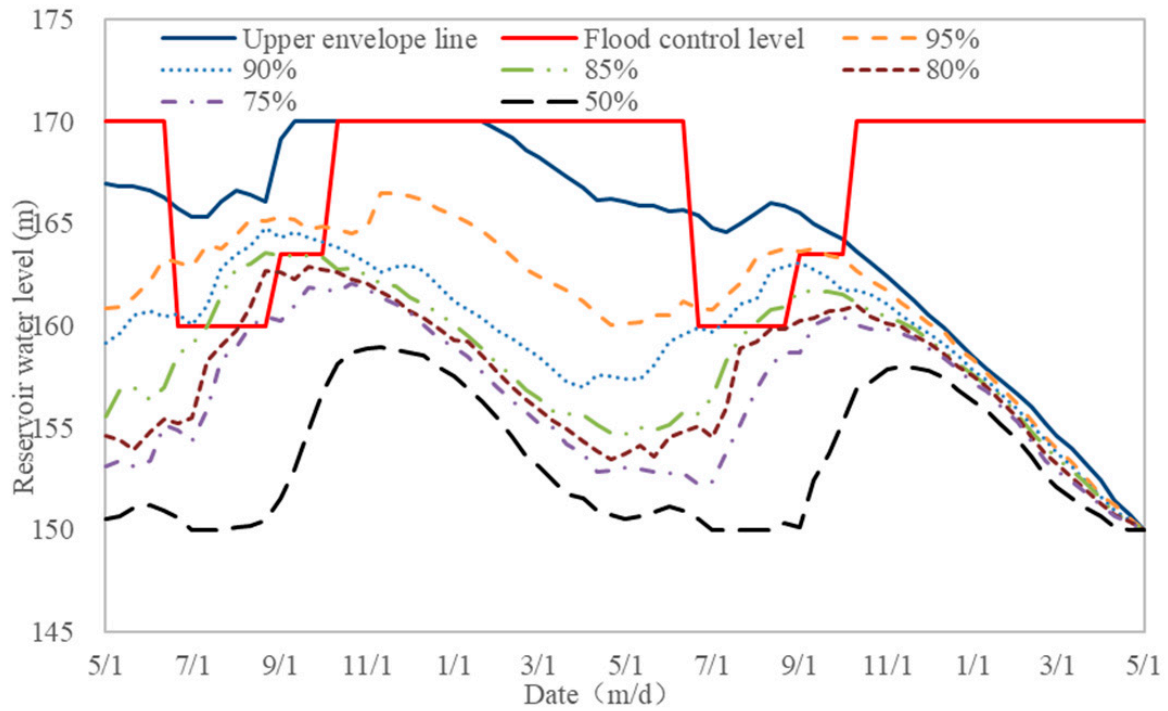

(b)

Figure 7. Water level control lines of Danjiangkou Reservoir under different water supply guarantee rates. (a) 1-year; (b) 2-year. 
The comprehensive analysis shows that, after the Danjiangkou Reservoir is heightened, to keep more than $95 \%$ of the years under normal water supply, given the water level subsides to the dead water level at the end of the water supply period, the water level shall be at least $162 \mathrm{~m}, 164.5 \mathrm{~m}$ and $165 \mathrm{~m}$ in 21 June, 21 August, and early October respectively; in case of continuous dry years in a typical year, it may take 1-2 years for impoundment to resume to the normal high water level, so as to ensure the water supply. To sum up, in order to guarantee the water supply in the later stage, the operating level in flood season must be higher than the flood limited water level.

\subsubsection{Analysis of Discharge Capacity}

Through the analysis of 30 typical historical floods, it is found that when heavy rainfall occurs at the upper reach of Hanjiang River and the flood reaches 10,000 $\mathrm{m}^{3} / \mathrm{s}$ in Danjiangkou Reservoir, the average time interval is $36 \mathrm{~h}$, and $24 \mathrm{~h}$ is taken for safety. The reliable forecast period of rainfall forecasts is 2 days, and the effective forecast period of Danjiangkou reservoir pre-discharge is 3 days.

With the flood discharge capacity of $11,000 \mathrm{~m}^{3} / \mathrm{s}\left(12,000 \mathrm{~m}^{3} / \mathrm{s}\right.$ in autumn $)$ at Huangzhuang as the boundary [27], the pre-discharge capacity of Danjiangkou reservoir in the 3-day forecast period is comprehensively analyzed by the typical historical flood process. Based on this, the pre-discharge capacity is more than 0.8 billion $\mathrm{m}^{3}$ in summer, equivalent to $1 \mathrm{~m}$ water level, and between $0.9-1.2$ billion $\mathrm{m}^{3}$ in autumn, equivalent to $1-1.5 \mathrm{~m}$ water level. The maximum forecast period is 7 days for medium-term forecasts. Assume the average discharges are $2280 \mathrm{~m}^{3} / \mathrm{s}$ and $420 \mathrm{~m}^{3} / \mathrm{s}$ at the inlet to Danjiangkou Reservoir and at Danjiangkou-Huangzhuang Section in the main flood season, it can be calculated that the pre-discharge capacity is about 1.4 billion $\mathrm{m}^{3}$ to control the flood discharge within $5000 \mathrm{~m}^{3} / \mathrm{s}$ at Huangzhuang, equivalent to around $1.5 \mathrm{~m}$ water level from a conservative perspective.

\section{Results and Discussion}

\subsection{Real-Time Forecast and Operation Schemes of Danjiangkou Reservoir}

\subsubsection{Indicators for Control of Water Level Rise by Stages}

Considering the staging characteristics of inflow floods into Danjiangkou Reservoir, when there is no flood control demand, combining with pre-discharge, water supply, and some other factors, the operating level may be increased properly in flood season, and the indicators for control of water level rise by stages in flood season are as shown in Table 4 .

\subsubsection{Pre-Discharge Forecast Scheme}

(1) Under the assumed condition of the current reservoir water level is above the floating control level, if rainfalls are forecasted in the next 10 days, it is required to immediately pre-discharge the reservoir to decrease the water level to the floating control level. The pre-discharging shall be performed by trying to control the discharge within $5000 \mathrm{~m}^{3} / \mathrm{s}$ at Huangzhuang or increasing the discharge to $8000 \mathrm{~m}^{3} / \mathrm{s}$ in case of extreme emergencies.

(2) Under the assumed condition of the current reservoir water level is above the floating control level, if medium or heavier rainfalls (accumulative rainfall $>30 \mathrm{~mm}$ for 3 days) are forecasted in the next 3 days, it is required to immediately pre-discharge the reservoir to decrease the water level to the floating control level. The pre-discharging shall be performed by trying to control the discharge within $8000 \mathrm{~m}^{3} / \mathrm{s}$ at Huangzhuang or increasing the discharge to $10,000 \mathrm{~m}^{3} / \mathrm{s}$ in case of extreme emergencies.

(3) Under the assumed condition of the current reservoir water level as above the floating control level, the rainfall begins and tends to aggravate subsequently, the predischarging forecasting may be performed by controlling the discharge between $5000-12,000 \mathrm{~m}^{3} / \mathrm{s}$ at Huangzhuang, and not greater than the safety discharge at the middle and lower reaches of Hanjiang River at that time. It is required to decrease the 
reservoir water level to the floating control level as soon as possible, or to the FLWL, if required.

(4) During pre-discharge forecasting, if the water level has been discharged to the floating water level, however, the heavy rainfall is still not coming, the inflow upstream has not been increased, and the situations are uncertain for flood control, it is possible to maintain the water level temporarily, and the pre-discharging or impoundment may be conducted according to the development of actual regime and rain conditions.

(5) In case of special requirements, the control water level indicators of Danjiangkou Reservoir may be adjusted properly based on the opinions of the flood control departments.

Table 4. Water level rise indicators of Danjiangkou Reservoir at different stages.

\begin{tabular}{|c|c|c|c|}
\hline Time Periods & Pre-Discharge & Water Supply & Water Level Rise Indicator \\
\hline 21 June-5 August & $\begin{array}{c}\text { About } 0.8 \text { billion } \mathrm{m}^{3} \text { of } \\
\text { pre-discharge capacity, equivalent } \\
\text { to around } 1 \mathrm{~m} \text { water level }\end{array}$ & $\begin{array}{l}\text { Impoundment to } 162 \mathrm{~m} \\
\text { on } 21 \text { June }\end{array}$ & $\begin{array}{c}\text { Water level rise by } 1 \mathrm{~m} \text { above } \\
\text { the flood limited water level, } \\
\text { namely, } 161 \mathrm{~m}\end{array}$ \\
\hline 6 August-20 August & $\begin{array}{l}\text { Low probability of floods at the } \\
\text { upper and middle reaches }\end{array}$ & $\begin{array}{l}\text { Impoundment properly } \\
\text { considered together with } \\
\text { the flood control }\end{array}$ & $\begin{array}{c}\text { Gradual transition to the flood } \\
\text { control level of } 163.5 \mathrm{~m} \text { in the } \\
\text { autumn flood season }\end{array}$ \\
\hline 21 August-31 August & $\begin{array}{c}\text { High probability of floods, } \\
\text { pre-discharge capacity taken as } \\
0.9 \text { billion } \mathrm{m}^{3} \text {, equivalent to about } \\
1 \mathrm{~m} \text { water level }\end{array}$ & $\begin{array}{l}\text { Impoundment to } \\
164.5 \mathrm{~m} \text { on } 21 \text { August }\end{array}$ & $\begin{array}{l}\text { Water level rise by } 1 \mathrm{~m} \text { above } \\
\text { the FLWL, namely, } 164.5 \mathrm{~m}\end{array}$ \\
\hline 1 September-15 September & $\begin{array}{l}\text { Reduced probability of floods, } \\
\text { water level decreased at Hankou, } \\
\text { pre-discharge capacity taken as } \\
1.2 \text { billion } \mathrm{m}^{3} \text {, equivalent to about } \\
1.5 \mathrm{~m} \text { water level }\end{array}$ & $\begin{array}{l}\text { Impoundment properly } \\
\text { considered together with } \\
\text { the flood control }\end{array}$ & $\begin{array}{l}\text { Mainly flood control, FLWL } \\
\text { rise by } 1.5 \mathrm{~m} \text {, namely, } 165 \mathrm{~m}\end{array}$ \\
\hline 16 September-30 September & $\begin{array}{l}\text { The analysis of many floods } \\
\text { including "October 1983" and } \\
\text { “October 1964" floods shows the } \\
\text { water level at around } 166 \mathrm{~m} \\
\text { imposes little impact on flood } \\
\text { control. }\end{array}$ & $\begin{array}{l}\text { The connection with the } \\
\text { water level demand by } \\
1 \text { October is considered. }\end{array}$ & $\begin{array}{l}\text { If there is no heavy rainfall } \\
\text { subsequently, to ensure the } \\
\text { impoundment, the flood } \\
\text { control water level may be } \\
\text { gradually raised to } 166 \mathrm{~m} \text {; and } \\
\text { then considering the } \\
\text { medium-term forecasts, the } \\
\text { water level may be increased } \\
\text { by } 1.5 \mathrm{~m} \text {, to } 167.5 \mathrm{~m}\end{array}$ \\
\hline 1 October & $\begin{array}{l}\text { With little inflow at } \\
\text { Danjiangkou-Huangzhuang } \\
\text { Section, the pre-discharging } \\
\text { capacity is up to } 0.93-1.7 \text { billion } \mathrm{m}^{3}\end{array}$ & $\begin{array}{l}\text { Impoundment to } 165 \mathrm{~m} \\
\text { by } 1 \text { October }\end{array}$ & $\begin{array}{l}\text { Based on the regime and rain } \\
\text { forecasts, Danjiangkou } \\
\text { gradually reaches } 170 \mathrm{~m} \\
\text { normal high-water level after } \\
\text { impoundment. }\end{array}$ \\
\hline
\end{tabular}

Notes: "October 1983" refers to the flood that occurred in October 1983. The return period of "October 1983" and "October 1964" floods is more than 20 years.

\subsubsection{Flood Control Operation Scheme}

(1) Operation for medium and small floods

The thresholds $11,000 \mathrm{~m}^{3} / \mathrm{s}, 12,000 \mathrm{~m}^{3} / \mathrm{s}$, and $16,000 \mathrm{~m}^{3} / \mathrm{s}, 17,000 \mathrm{~m}^{3} / \mathrm{s}$ are respectively used to determine whether Dujiatai flood diversion is included in Huangzhuang flood control and discharging scheme (summer and autumn) or not. The most adverse flood occurred at each stage is considered as the criterion for subsequent precautions after detaining the medium or small flood, to calculate the allowable maximum initial water level after the regulation for small and medium flood control, with the results as shown in Table 5. 
Table 5. Water level indicators used in operation for medium and small floods.

\begin{tabular}{|c|c|c|c|c|c|c|}
\hline \multirow{3}{*}{ Flood Season } & \multicolumn{3}{|c|}{ Discharging at $11,000,12,000 \mathrm{~m}^{3} / \mathrm{s}$ for Flood Control at Huangzhuang } & \multicolumn{3}{|c|}{$\begin{array}{c}\text { Discharging at } 16,000,17,000 \mathrm{~m}^{3} / \mathrm{s} \text { for Flood Control at } \\
\text { Huangzhuang }\end{array}$} \\
\hline & \multicolumn{2}{|c|}{ Most Adverse Scenario } & \multirow{2}{*}{$\begin{array}{l}\text { Allowable Maximum } \\
\text { Initial Water Level for } \\
\text { Reservoir Operation (m) }\end{array}$} & \multicolumn{2}{|c|}{ Most Adverse Scenario } & \multirow{2}{*}{$\begin{array}{l}\text { Allowable Maximum } \\
\text { Initial Water Level for } \\
\text { Reservoir Operation (m) }\end{array}$} \\
\hline & Flood Date & $\begin{array}{l}\text { Flood Discharge } \\
\text { Excess }\left(10^{8} \mathrm{~m}^{3}\right)\end{array}$ & & Flood Date & $\begin{array}{l}\text { Flood Discharge } \\
\text { Excess }\left(10^{8} \mathrm{~m}^{3}\right)\end{array}$ & \\
\hline \multirow{2}{*}{$\begin{array}{l}21 \text { June- } 5 \text { August } \\
6 \text { August-20 } \\
\text { August }\end{array}$} & July 2010 & 56.81 & 166.09 & July 2010 & 19.59 & 169.85 \\
\hline & August 1958 & 21.36 & 169.67 & August 1958 & 7.92 & 170.96 \\
\hline $\begin{array}{l}21 \text { August-31 } \\
\text { August }\end{array}$ & August 2005 & 26.17 & 169.21 & August 2005 & 11.09 & 170.66 \\
\hline $\begin{array}{l}1 \text { September-15 } \\
\text { September }\end{array}$ & September 2003 & 42.72 & 167.55 & $\begin{array}{l}\text { September } \\
1960\end{array}$ & 37.24 & 168.11 \\
\hline $\begin{array}{l}16 \text { September-30 } \\
\text { September }\end{array}$ & September 1964 & 44.29 & 167.37 & $\begin{array}{l}\text { September } \\
1984\end{array}$ & 15.62 & 170.23 \\
\hline
\end{tabular}

\section{(2) Flood control operation scheme}

Floods in typical years are fully considered according to the inflow flood peaks, maximum flood volume of $7 \mathrm{~d}, 15 \mathrm{~d}$, and $30 \mathrm{~d}$ and historical ranks. Different flood magnitudes can be divided. The compensative regulations at the middle and lower reaches are simulated as stated in Section 3.4.1. In accordance with the Procedures [27], the realtime flood control operation scheme of Danjiangkou Reservoir is summarized, as shown in Table 6.

Table 6. Regulations for real-time flood control of Danjiangkou Reservoir.

\begin{tabular}{|c|c|}
\hline Upstream Flood Frequency & Flood Control Indicator \\
\hline$>100$-year return period & Operation as per the Procedures \\
\hline $\begin{array}{l}\quad>50 \text {-year return period } \\
\leq \text { July } 1935 \text { flood magnitude }\end{array}$ & $\begin{array}{c}\text { Compensative operation, to control the discharge between } 20,000 \mathrm{~m}^{3} / \mathrm{s} \sim 21,000 \mathrm{~m}^{3} / \mathrm{s} \text { at } \\
\text { Huangzhuang, and reduce the flood water level below } 171.7 \mathrm{~m} \text { at Danjiangkou } \\
\text { Reservoir }\end{array}$ \\
\hline 20-50-year return period & $\begin{array}{c}\text { Compensative operation, to control the discharge between } 17,000 \mathrm{~m}^{3} / \mathrm{s} \sim 20,000 \mathrm{~m}^{3} / \mathrm{s} \text { at } \\
\text { Huangzhuang, and reduce the flood water level below } 171.7 \mathrm{~m} \text { at Danjiangkou } \\
\text { Reservoir }\end{array}$ \\
\hline 10-20-year return period & $\begin{array}{l}\text { Compensative operation, to control the discharge between } 12,000 \mathrm{~m}^{3} / \mathrm{s} \sim 17,000 \mathrm{~m}^{3} / \mathrm{s} \text { at } \\
\text { Huangzhuang, and regulate the flood water level within the normal high-water level of } \\
\qquad 170 \mathrm{~m} \text {, at Danjiangkou Reservoir }\end{array}$ \\
\hline$<10$-year return period & $\begin{array}{l}\text { Compensative operation, to control the discharge between } 8000 \mathrm{~m}^{3} / \mathrm{s} \sim 12,000 \mathrm{~m}^{3} / \mathrm{s} \text { at } \\
\text { Huangzhuang, and regulate the flood water level below } 167 \mathrm{~m} \text { in summer and } 168.6 \mathrm{~m} \\
\text { in autumn at Danjiangkou Reservoir }\end{array}$ \\
\hline
\end{tabular}

Notes: The highest level of Danjiangkou Reservoir in history is $167 \mathrm{~m}$, and the upper water level for flood control is $171.7 \mathrm{~m}$.

If continuous rainfalls are forecasted but it is difficult to identify the flood magnitude, the above real-time control scheme may be followed step by step, to enable the regulation for flood control targeting to restrain the discharge within $8000 \mathrm{~m}^{3} / \mathrm{s}, 10,000 \mathrm{~m}^{3} / \mathrm{s}$, $12,000 \mathrm{~m}^{3} / \mathrm{s}, 16,000 \mathrm{~m}^{3} / \mathrm{s}, 18,000 \mathrm{~m}^{3} / \mathrm{s}$, and $20,000 \mathrm{~m}^{3} / \mathrm{s}$ at Huangzhuang, for the purpose of relieving the downstream flood control stress as practicable as possible, and to shift the regulation mode depending on the water inflow as stated in the Procedures.

In case of any flood with the magnitude same as August 1954 flood (with a return period of 10-20 years) or August 1998 flood (with a return period of 5-10 years), it will lead to a higher water level in Hankou. The flood detention and peak shifting are necessary at Danjiangkou Reservoir. Based on the real-time rainfall and flood forecasts, Danjiangkou Reservoir may share the flood control stress, as appropriate, with the main stream of Yangtze River.

\subsection{Practice of Dynamic Control Operation of Danjiangkou Reservoir}

The autumn flood season in 2017 is taken as an example to describe the dynamic control operation of Danjiangkou Reservoir, as shown in Figure 8 and Table 7 which list the 
statistics of characteristic values for flood control regulation in the autumn flood season in 2017.

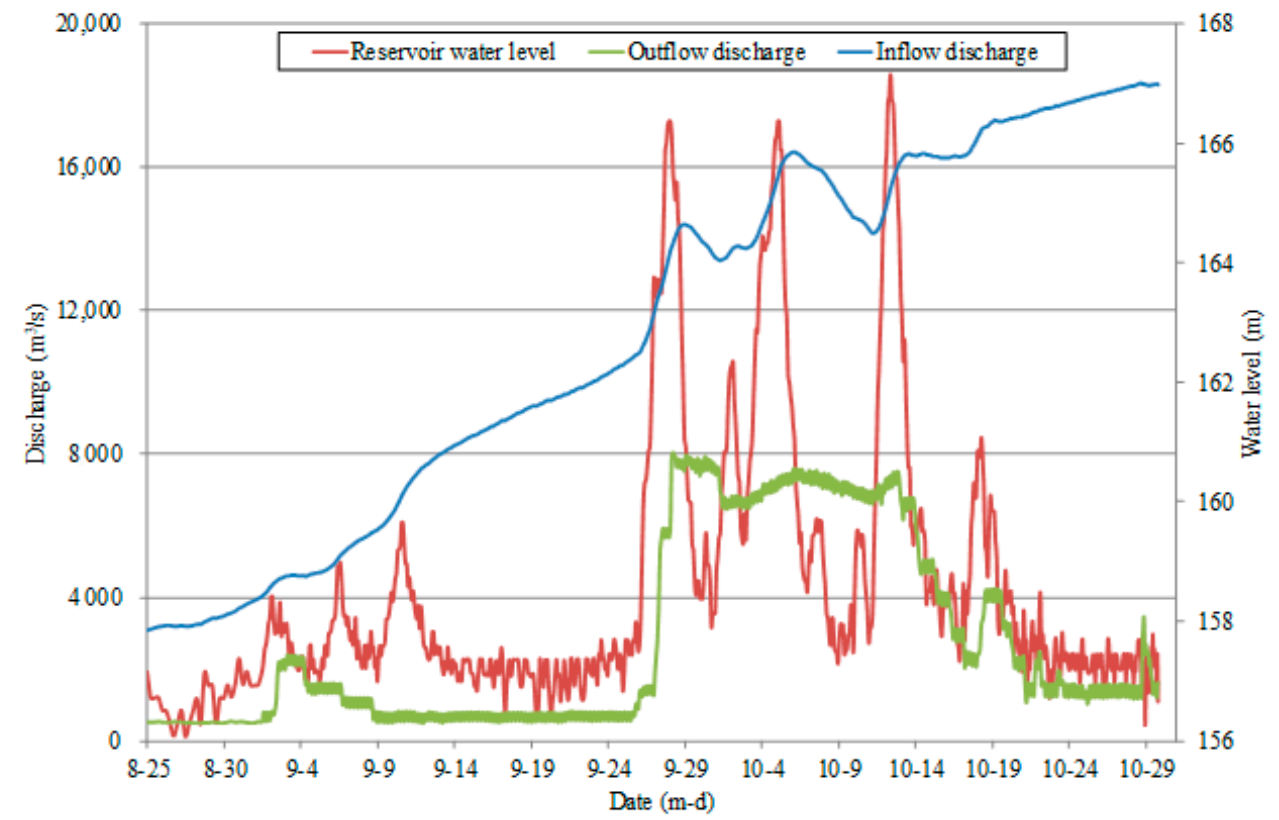

Figure 8. Process of inflow, outflow and water levels of Danjiangkou Reservoir in the autumn flood season in 2017.

Table 7. Flood control operation for autumn floods in 2017 at Danjiangkou Reservoir.

\begin{tabular}{|c|c|c|c|c|c|}
\hline Flood Peak Time & $\begin{array}{l}\text { Inflow Flood } \\
\text { Peak }\left(\mathrm{m}^{3} / \mathrm{s}\right)\end{array}$ & $\begin{array}{c}\text { Maximum } \\
\text { Outflow } \\
\text { Discharge }\left(\mathrm{m}^{3} / \mathrm{s}\right)\end{array}$ & $\begin{array}{c}\text { Peak } \\
\text { Reduction } \\
\text { Rate (\%) }\end{array}$ & $\begin{array}{l}\text { Maximum Water } \\
\text { Level for Flood } \\
\text { Regulation (m) }\end{array}$ & $\begin{array}{c}\text { Maximum Flood } \\
\text { Discharge after } \\
\text { Impoundment }\left(10^{8} \mathrm{~m}^{3}\right)\end{array}$ \\
\hline 10:00 on 28 September & 17,300 & 8040 & 53.5 & 164.63 & 21.14 \\
\hline 12:00 on 5 October & 17,300 & 7600 & 56.1 & 165.85 & 15.0 \\
\hline 18:00 on 12 October & 18,600 & 7550 & 59.4 & 165.82 & 11.71 \\
\hline
\end{tabular}

Notes: The Flood Peak No. is defined according to the occurrence time of the first flood peak.

From September to October 2017, the subtropical high was unusually strong and northerly, and the westerly trough moved eastward continuously. Cold air moved southward, mixing warm and cold air. These resulted in three significant rainfall processes at the upper reach of the Hanjiang River, with heavy rainfalls to rainstorms in most areas. Under this impact, Danjiangkou Reservoir saw 3 floods with inflow flood peaks above $17,000 \mathrm{~m}^{3} / \mathrm{s}$, the annual maximum inflow flood discharge of $18,600 \mathrm{~m}^{3} / \mathrm{s}$ and the maximum $15 \mathrm{~d}$ flood discharge of 11.03 billion $\mathrm{m}^{3}$, equivalent to a 10 -year flood in autumn. At the same time, Danjiangkou-Huangzhuang Section also witnessed the water level rising for many times, with the maximum flood discharge of $7000 \mathrm{~m}^{3} / \mathrm{s}$ and the maximum $7 \mathrm{~d}$ flood discharge of 2.32 billion $\mathrm{m}^{3}$, surpassing the 20 -year flood in autumn. At the middle and lower reaches of the mainstream, the water levels at many stations also rose significantly and over the warning water level, with the maximum rise of more than $11 \mathrm{~m}$.

During autumn flood seasons, the short-term 1-2 d forecasts for the inflow discharge of Danjiangkou Reservoir have the relative forecast error within 15\%. The forecasts at flood peak magnitude have a forecast period up to $10 \mathrm{~d}$, enabling the above-warning-level forecast $4 \mathrm{~d}$ early at main stations in the middle and lower reaches. The near-term flood peak level forecast has error within $0.15 \mathrm{~m}$. According to the forecast and operation scheme in Section 4.1, dynamic control and operation such as water level rising, peak shifting, and peak clipping have been implemented. The remarkable comprehensive benefits have 
been achieved. During the flood with three peaks greater than $17,000 \mathrm{~m}^{3} / \mathrm{s}$, the flood retention and peak reduction was carried out at Danjiangkou Reservoir under the premise of ensuring the safety of flood control and the project. The maximum outflow discharge is $8040 \mathrm{~m}^{3} / \mathrm{s}$, the reduction rates for these 3 peaks are above $50 \%$. The maximum flood regulation level is up to $165.85 \mathrm{~m}$, and the accumulative maximum flood storage and detention is 4.78 billion $\mathrm{m}^{3}$. As a result, the flood peak level of the main stations at the middle reach of Hanjiang River decreased by about $2 \mathrm{~m}$, avoiding multiple stations exceeding the safety water level. At the same time, the flood diversion dikes and Dujiatai flood diversion area were avoided, which significantly reduced the flood control pressure at the lower reach of Hanjiang River. According to incomplete statistics, the flood control benefit is about 0.704 billion yuan. From September to October, the water supply volumes are 1.289 billion $\mathrm{m}^{3}$ and 0.253 billion $\mathrm{m}^{3}$, respectively in Taocha and Qingquan Valleys, overfulfilling the water supply mission for this period. At the end of the flood season, the impoundment level is the record high $167 \mathrm{~m}$, not only creating the conditions for the dam safety monitoring, but also laying fundament for water supply and ecological benefits of the next year.

\section{Conclusions}

For dynamic control of operating levels in flood season, this paper researched and proposed a practicable technical system at the real-time operation level. Taking Danjiangkou reservoir as an example, a real-time forecast and operation scheme was developed. This scheme can provide technical support for ensuring the overall benefits of Danjiangkou Reservoir, such as flood control, water supply, and power generation. The following conclusions are made:

(1) The inflow floods have staging features and will experience a development process; therefore, different regulation strategies may be taken for floods in development process at different stages of the flood season.

(2) The modern forecast technologies integrate long-, medium-, and short-term forecasts and couple meteorological and hydrological conditions. They can increase the flood foreseeability and make it possible for dynamic control of reservoirs.

(3) The reservoir has the contradiction between impoundment and flood control, and upon the forecast information, by taking risks properly, scientific regulation decisions should be made to ensure the flood control safety and give full play to overall benefits.

(4) The proposed practical technical system is generally applicable, and may be taken as the reference for real-time application of dynamic control of reservoir operating levels in flood season.

Author Contributions: Conceptualization, J.Z.; Methodology, Y.M.; Supervision, Y.M.; Validation, B.F. and W.D.; Writing-Original draft, J.Z., B.F. and W.D.; Writing-Review \& Editing, J.Z. All authors have read and agreed to the published version of the manuscript.

Funding: This research has been supported by the National Key Research and Development Program of China (2021YFC3200301), National Natural Science Foundation of China (51779176).

Institutional Review Board Statement: Not applicable.

Informed Consent Statement: Not applicable.

Conflicts of Interest: The authors declare no conflict of interest. 


\section{References}

1. Wei, C.C.; Hsu, N.S. Multi-reservoir real-time operations for flood control using balanced water level index method. J. Environ. Manag. 2008, 88, 1624-1639. [CrossRef] [PubMed]

2. Labadie, J.W. Optimal operation of multi-reservoir systems: State-of-the-art review. J. Water Resour. Plan. Manag. 2004, 130, 93-111. [CrossRef]

3. Qiu, R.; Wang, B.; Zhou, H. New Idea for controlling the limited elevation of reservoirs in flood season. Adv. Water Sci. 2004, 15, 68-72.

4. Ren, M.; He, X.; Huang, J.; Li, H. Real-time Dynamic Control of reservoir water Level in flood season and its risk analysis based on short-term rainfall forecast information. J. Hydraul. Eng. 2013, 43, 66-72. (In Chinese)

5. Li, X.; Guo, S.; Liu, P.; Liu, X. Schemes of storage level control of Three Georges Reservoir during flood seasons. J. Hydroelectr. Eng. 2010, 29, 102-107.

6. Yuan, J.; Wang, B.; Wang, F.; Li, F. Study on real-time dynamic operation of reservoir water level in flood season based on short-term rainfall forecast information. J. Hydroelectr. Eng. 2008, 27, 15-19.

7. Zhou, X.; Min, Y.; Feng, B.; Li, Y. Application of small and medium-sized floods real-time forecasting and operation technology for large reservoir in the Three Georges Reservoir. J. China Hydrol. 2011, 37, 180-184.

8. Chen, G.; Guo, S. Dynamic operation of reservoir for small and median inflows in flood season. J. Hydroelectr. Eng. 2012, 31, 6.

9. Li, Y.; Xia, Q.; Chang, W.; Li, Q.; Wang, L.; Islam, M.S. Review of the methods of the reservoir's limiting water level during flood season. J. Water Resour. Water Eng. 2020, 31, 127-134.

10. US Army Corps of Engineers. HEC-5, Simulation of Flood Control and Conservation Systems; User's Manual Version 8.0; Hydrologic Engineering Center: Davis, CA, USA, 1998.

11. Wurbs, R.A.; Cabezas, L.M. Analysis of reservoir storage reallocations. J. Hydrol. 1987, 92, 77-95. [CrossRef]

12. Cunderlik, J.M.; Ouarda, T.B.; Bobee, B. Determination of flood seasonality from hydrological records. Hydrol. Sci. J. 2004, 49, 511-526. [CrossRef]

13. Beurton, S.; Thieken, A.H. Seasonality of floods in Germany. Hydrol. Sci. J. 2009, 54, 62-76. [CrossRef]

14. Chang, L.C. Guiding rational reservoir flood operation using penalty-type genetic algorithm. J. Hydrol. 2008, 354, 65-74. [CrossRef]

15. Malekmohammadi, B.; Zahraie, B.; Kerachian, R. A real-time operation optimization model for flood management in riverreservoir systems. Nat. Hazards 2010, 53, 459-482. [CrossRef]

16. Che, D.; Mays, L.W. Development of an optimization/simulation model for real-time flood-control operation of river-reservoirs systems. Water Resour. Manag. 2015, 29, 3987-4005. [CrossRef]

17. Ashofteh, P.S.; Haddad, O.B.; Loaiciga, H.A. Evaluation of climatic-change impacts on multi-objective reservoir operation with multi-objective genetic programming. J. Water Resour. Plan. Manag. 2015, 141, 1-11. [CrossRef]

18. Ahmadi, M.; Haddad, O.B.; Loaicigu, H.A. Adaptive reservoir operation rules under climatic change. Water Resour. Manag. 2015, 29, 1247-1266. [CrossRef]

19. Loucks, D.P.; Van Beek, E. Water Resource Systems Planning and Management: An Introduction to Methods, Models, and Applications; Springer: Ithaca, NY, USA, 2017.

20. Liu, P.; Li, L.; Guo, S.; Xiong, L.; Zhang, W.; Zhang, J.; Xu, C. Optimal design of seasonal flood limited water levels and its application for the Three Gorges Reservoir. J. Hydrol. 2015, 527, 1045-1053. [CrossRef]

21. Li, X.; Guo, S.; Liu, P.; Chen, G. Dynamic control of flood limited water level for reservoir operation by considering inflow uncertainty. J. Hydrol. 2010, 391, 124-132. [CrossRef]

22. Yun, R.; Singh, V.P. Multiple duration limited water level and dynamic limited water level for flood control with implication on water supply. J. Hydrol. 2008, 354, 160-170. [CrossRef]

23. Rani, D.; Mourato, S.; Moreira, M. A Generalized Dynamic Programming Modelling Approach for Integrated Reservoir Operation. Water Resour. Manag. 2020, 34, 1335-1351. [CrossRef]

24. Chen, J.; Guo, S.; Li, Y.; Liu, P.; Zhou, Y. Joint operation and dynamic control of flood limiting water levels for cascade reservoirs. Water Resour. Manag. 2013, 27, 749-763. [CrossRef]

25. Jiang, Z.; Sun, P.; Ji, C.; Zhou, J. Credibility theory based dynamic control bound optimization for reservoir flood limited water level. J. Hydrol. 2015, 529, 928-939. [CrossRef]

26. Wang, B.; Zhou, H.; Wang, G. Theory, Method and Application on Dynamic Control of Reservoir Limit Water Level; China Water Power Press: Beijing, China, 2006.

27. Changjiang Water Resources Commission of the Ministry of Water Resources. Procedures for Regulation of Danjiangkou Water Conservancy Hinge Project (Trial); Changjiang Water Resources Commission of the Ministry of Water Resources: Wuhan, China, 2016; p. 9.

28. Ding, S.; Zhang, L.; Zhang, M. Division of flood seasonal phases for Yangtze River basin and its scientific supporting role in the optimization of reservoir impoundment process. J. China Hydrol. 2012, 32, 62-68.

29. Liu, P.; Guo, S.; Wang, C.; Zhou, F. Optimization of limited water level in flood season and impounding scheme for reservoir in Three Gorges Project. J. Hydraul. Eng. 2004, 7, 86-91. (In Chinese) 
30. General Administration of Quality Supervision \& Inspection and Quarantine of the People's Republic of China, National Standardization Management Committee of China. Standard for Hydrological Information and Hydrological Forecasting (GB/T 22482-2008); Water Resources of the People's Republic of China, Standards Press of China: Beijing, China, 2008 ; p. 12.

31. Changjiang Water Resources Commission. China Rivers and Lakes (Volume of Yangtze River); China Water Power Press: Beijing, China, 2010.

32. Liu, G.; Qin, H.; Shen, Q.; Tian, R.; Liu, Y. Multi-Objective Optimal Scheduling Model of Dynamic Control of Flood Limit Water Level for Cascade Reservoirs. Water 2019, 11, 1836. [CrossRef]

33. Changiiang Institute of Survey, Planning, Design and Research. General Report on Feasibility Study of South-to-North Water Diversion Middle Route (Phase I) Project; Changjiang Institute of Survey, Planning, Design and Research: Wuhan, China, 2005. 